\title{
AUTOMATED SYSTEM TO DETECT RF LEAKAGE FROM MICROWAVE OVEN USING RASPBERRY PI
}

\author{
N M Chavan', A M Deshmukh², A S Kulkarni ${ }^{3}$ \\ ${ }^{1}$ M.E. Communication Networks, Sinhgad College of Engineering, Pune, India \\ ${ }^{2}$ Dept. of E\&TC, Sinhgad College of Engineering, Pune, India \\ ${ }^{3} R \& D$ Engineer, Akademica group, Mumbai, India
}

\begin{abstract}
The microwave oven is a kitchen appliance which is used in day to day life. After long use of oven there is leakage of microwave radiations takes place. These radiations are hazardous to human being. Number of people use microwave ovens every year and make themselves vulnerable to risk. This system detects the leaked radiations. It checks those leaked radiations for the threshold value. If these radiations are found to be above the threshold value, then the system informs to their respective owner and manufacturer about leakage. So they can take appropriate action regarding the issue.
\end{abstract}

Keywords: Leakage detection, MAR 3 Amplifier, MCP 3008, Microwave Oven, Raspberry Pi

****

\section{INTRODUCTION}

Microwave heating systems have been widely developed for industrial applications especially for food and agricultural products. In 1945 the patent of microwave oven is launched by Percy Spencer. Until 1967 as it is not affordable it is barely available for domestic use. In the microwave ovens food is heated quickly and efficiently. They do not cook the food as conventional ovens do. Due to this it is not good to cook certain foods. It is also difficult to achieve certain culinary effects. The apparent cooking advantages of the microwave oven assured that its uptake would be rapid. It is ample with up to 90 percent of the western world's households currently owning one. Earlier ovens are based on accurate engineering of door and metal-to-metal contact i.e. hinge where the door is closed. This design enables higher levels of leakage that increase when the door connection became dirty or misplaced. Later door design changed to include a quarter wavelength choke that successfully created a short circuit at the door to oven interface and that circuit helps to prevent radiation leakage. The application of a quarter wavelength choke helps to maintain clean metal-tometal contact and permit small gaps at the door interface.

Microwave oven leakage can have disastrous effects. Daily use of microwave ovens can cause various problems such as temporary sterility, skin cancer, serious eye damage, cardiovascular problems and central nervous system damage. Number of people use microwave ovens every year and make themselves vulnerable to risk. Due to this problem it is important to perform measurements of electromagnetic energy leakage. The current emission limit for microwave oven is based on an approach taken in 1968 where the upper limit of microwave leakage should be related to the American National Standards Institute (ANSI). This was done in a conventional way by applying the whole body exposure limit of $10 \mathrm{~mW} / \mathrm{cm}^{2}$ for an exposure occurring at a distance of 5 $\mathrm{cm}$ from the external surface of the microwave oven. From the beginning it was well understood that compliance with the emission specification gave a large margin of safety when considering the exposure of a person operating a leaky microwave oven. The US Bureau of Radiological Health $(\mathrm{BRH})$ further tighten the emission limit and adopt a standard that specified an emission limit of $1 \mathrm{~mW} / \mathrm{cm}$ at $5 \mathrm{~cm}$ at manufacture and $5 \mathrm{~mW} / \mathrm{cm}$ at $5 \mathrm{~cm}$ after sale. This standard is still in place in the US and Canada. In 1971 the $5 \mathrm{~mW} / \mathrm{cm}$ at $5 \mathrm{~cm}$ emission standard was adopted in Australia by the National Health and Medical Research Council. In 1976 the International Electro technical Commission (IEC) issued an emission standard of $5 \mathrm{~mW} / \mathrm{cm}^{2}$ at $5 \mathrm{~cm}$

The $5 \mathrm{~mW} / \mathrm{cm}$ at $5 \mathrm{~cm}$ exposure limit was written into an Australian Standards Association in 1978 as an acceptance and test specification. It was derived from the IEC standard. According to Australian radiation protection and nuclear safety agency (ARPANSA) annual leakage testing of microwave ovens is not required. Ovens only need to be tested for leakage following repair or if damage is suspected. While it is possible for microwave ovens that appear in acceptable working condition to leak microwave levels that exceed the emission limit.

The rest of paper is organized as follows. Section 2 will present a brief current scenario for leakage detection. Section 3 consists of system block diagram is explanation. Section 4 contains experimental results of the system. Finally section 5 has the conclusion of our proposed design.

\section{PRESENT RF LEAKAGE SENSING APPLIANCES AND THEIR LIMITATIONS}

At present some radiation detecting devices are available in the market. These devices are manually operating devices. Those devices always needs a person to operate them. The 
following fig 1 depicts one of the manual operating device. The system shown

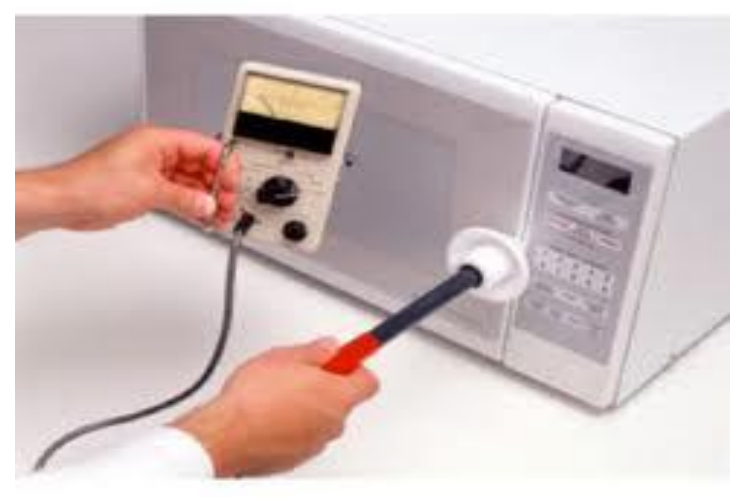

Fig 1: Present Radiation Detection System.

has analog meter which gives reading of leakage. It has loop antenna which needs to be moved in front of oven door within the range of $5 \mathrm{~cm}$. This antenna is connected to the analog meter to get the readings. Accuracy of the analog meter is less, hence digital meter is developed. Digital meter is developed in such a way that it has inbuilt antenna, amplifier circuit along with display which makes it a complete handheld device. Some advance meters possess buzzer.There are some issues concerning present system which are as:

It is not continuous monitoring system. It is based on periodic monitoring. Monitoring period is around 6 months or 1 year which depends on oven manufacturer. In between two service periods if the leakage occurred then there is no any other way to detect it. With the usage of present system it is not possible to provide instant service incase if there any leakage occurred. It is time consuming process. This may cause harm to user. Technical person is required to service the oven and hence to detect the radiations. In this system we need to contact the manufacturer regarding the service to repair the device. We cannot store the leakage amount in the present system as it varies according to the food items. The reading of the meter is solely depends on the how you place it in front of the microwave oven while taking readings. If it is not placed properly then it may show incorrect readings. Due to which the user may be misguided.

\section{SYSTEM BLOCK DIAGRAM}

The proposed system is shown in fig 2 . There are two blocks in the system, which are as follows:

1. Radio Frequency Section (named as RF FRONT END)

2. Processing section

Input section consists of patch antenna. Here patch antenna does the work of receiver it receives all the radiation which are then used as input to the system. It is most important part of the system as it acts as input device for the system. Processing section consists of MMIC Amplifier, Schottky Detector, Analog to Digital Converter and Raspberry-Pi and the output section consist of GSM, internet, LED and buzzer. As shown in the diagram, the electromagnetic radiation frequency is $2.4 \mathrm{GHz}$. The gain is variable but for the simplicity we have taken it as $-65 \mathrm{dBM}$. To detect the leakage from oven we need a sensor which can work at 2.4 GHz. There are few antennas which can work at this frequency. The antenna here works as a sensor of the system. Here system uses patch antenna with the gain of $6 \mathrm{~dB}$ as shown in the fig2. We used patch antenna here because it is having more advantages and better prospect. They are lighter in weight, smaller in dimension, provide dual and circular polarization and broad bandwidth.

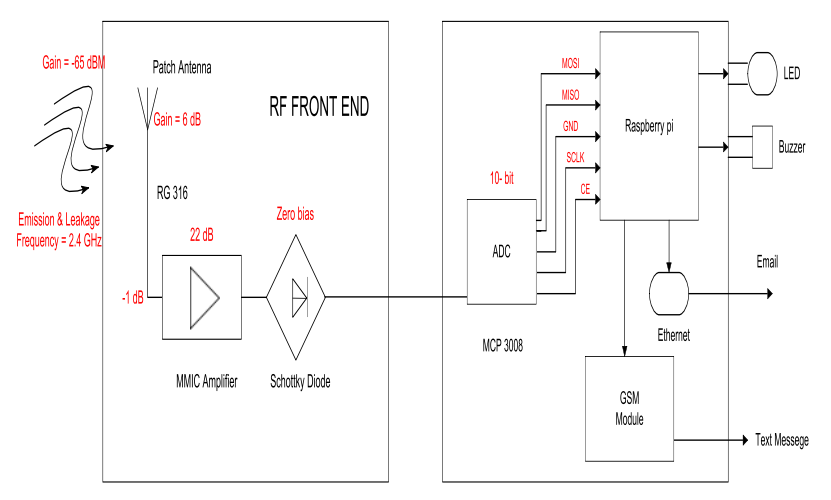

Fig. 2: Block diagram of the system.

RG316 is a coaxial single shielded cable having impedance $50 \mathrm{Ohms}$. It is used as medium for transferring the signal from antenna to the MMIC amplifier via SMA connector. The SMA connector here connects the path between antenna and MMIC amplifier. The gain of this cable is $-1 \mathrm{~dB}$ as shown in the fig2. Capacitance of the cable is $29 \mathrm{pF} / \mathrm{feet}$. Attenuation of the cable is $58 \mathrm{~dB} / 100 \mathrm{ft}$. This cable works upto $3 \mathrm{GHz}$ frequency and this system works on $2.4 \mathrm{GHz}$ and therefore we used this cable for the system.

MMIC stands for Microwave Monolithic Integrated Circuits. MMIC has capacity to overcome problems such as selfoscillation, instability and impedance mismatch. MMICs generally use the 4 leads configuration, input, output with power supply and two gound connections. Here system uses MAR 3 amplifier which works at $2.4 \mathrm{GHz}$. Maximum gain for the MAR 3 amplifier is $22 \mathrm{~dB}$. Here input impedance matching is 50 Ohms. For proper functioning of this amplifier DC blocking capacitor is needed at the input as well as at the output. The signal from the MAR 3 amplifier the signal goes to the schottky detector. This signal is then converted to DC by schottky detector. This works at zero bias which requires no external power when attached with antenna for receiving purpose. The signal from schottky detector is then transmitted to 10 bit ADC. The system uses MCP 3008 A to D converter which is based on serial peripheral interface(SPI). Clock pin is necessary for this ADC.

Raspberry Pi is nothing but the single chip computer. It can process any kind of data in it. It cannot read analog data that's why ADC is required in the initial stage of the system. 


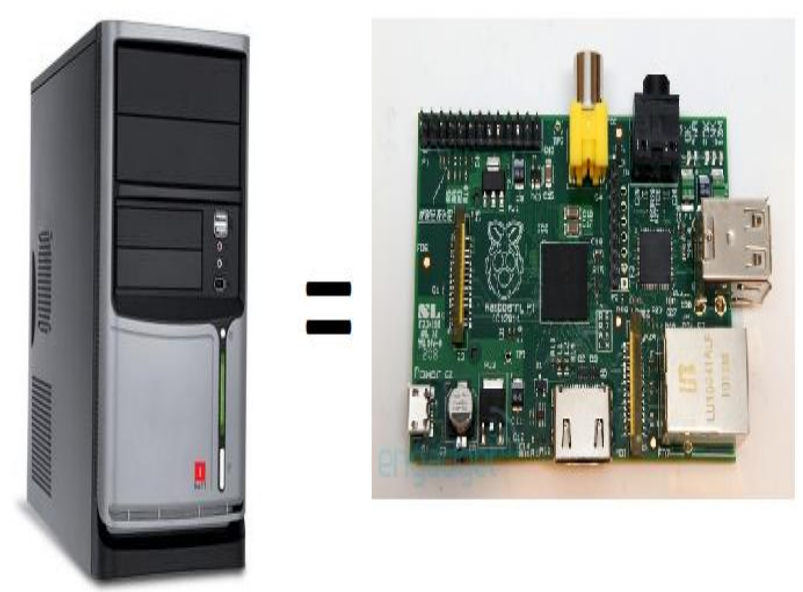

Fig 3: On chip system.

It reads the signal from the ADC. If it is above the threshold level then the system realize that radiation has occurred. Then LED will glow and buzzer will start ringing. To inform the manufacturer and the user the Raspberry Pi will send email and text message to them.

\section{RESULTS}

Simulations for the antenna are carried out using ADS which is a commercial electromagnetic simulator. It is based on an integral equation method and the method of moment. For the patch antenna there is no major change in the resonance frequency but VSWR and return loss are observed as a good agreement at $2.4 \mathrm{GHz}$ with return loss $-25 \mathrm{~dB}$ and VSWR 1.2. Return loss of the antenna is shown in the following fig5.

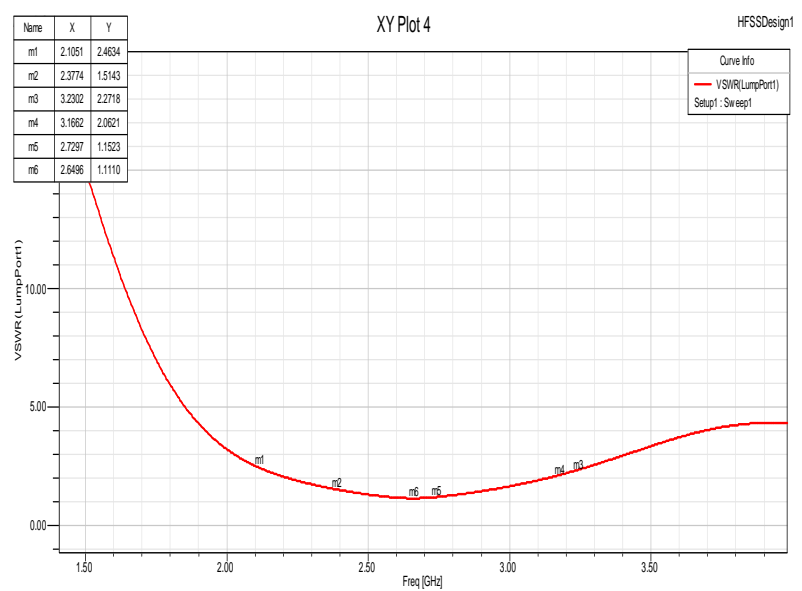

Fig 4: VSWR of the antenna at $2.4 \mathrm{GHz}$.

The programs for LED and BUZZER are tested successfully using Raspberry Pi. Fig 5 shows the LED is glowing using raspberry P. Similarly e-mail sending is also working properly on the system. Fig 6 shows ADC readings at different reference voltage and different input voltage.

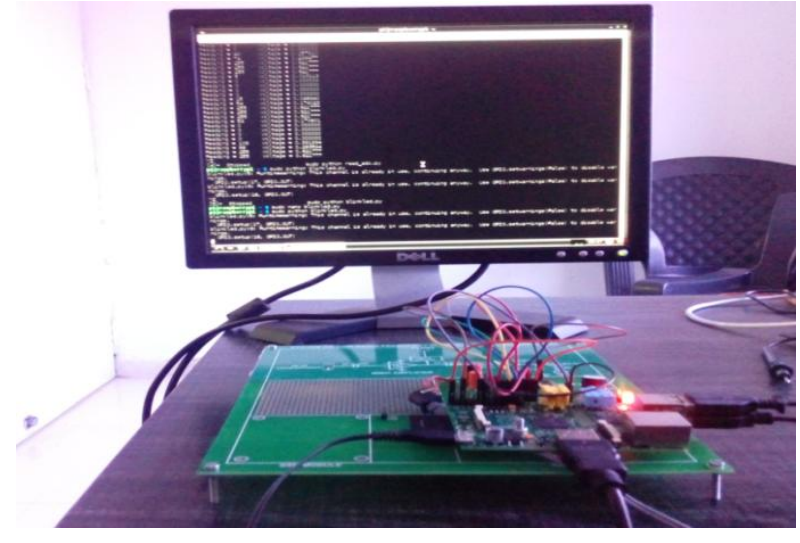

Fig 5: LED glowing using Raspberry pi

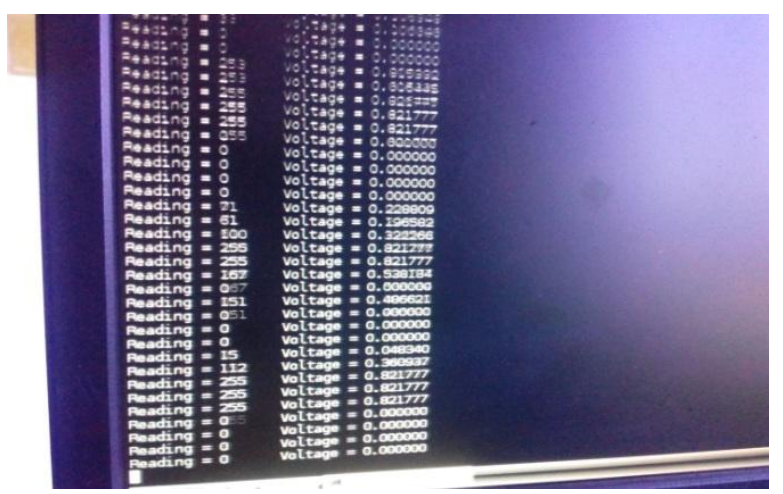

Fig 6: ADC Readings on monitor.

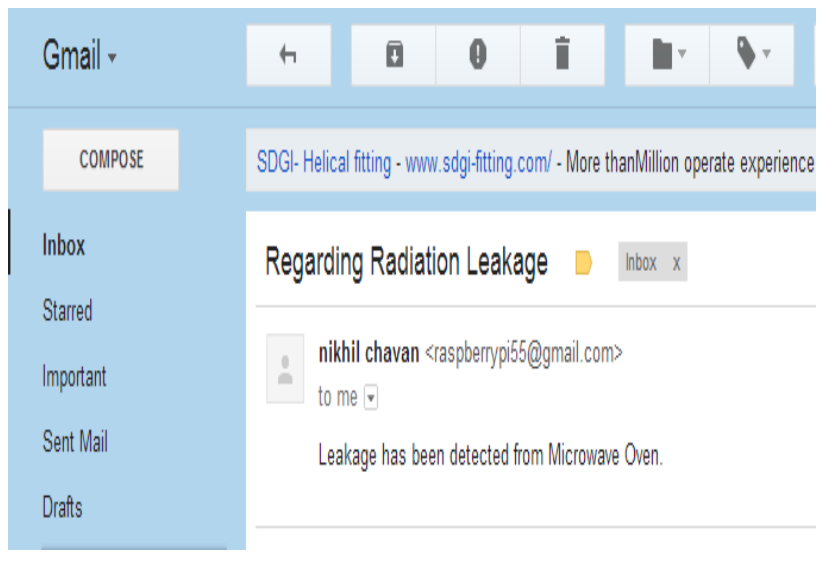

Fig 7: Received e-mail.

Fig 7 shows that e-mail is received successfully which is sent by the system. These three functional modules are tested individually.

\section{CONCLUSIONS}

This system is independent and robust. The system can be calibrated as it is having Raspberry $\mathrm{Pi}$ which acts as a processor. Because of this we can get accurate reading in any working environment. This is fully automatic system which does not need any manual interference, hence manual errors are eliminated. Hence accuracy of the system is increased. 


\section{REFERENCES}

[1] M. Bangay,C. Zombolas, "Advanced Measurements of Microwave Oven Leakage", Australian Radiation Protection and Nuclear safety Agency,2004.

[2] WEN Yinghong, ZHANG Linchang, LIU Chen, ZHANG Xiaodong, "Measurement and Calculation Of The Radiation Characteristics Of Microwave Oven" EMC Research Section Northern Jiaotong University Beijing, China proceeding IEEE 2003

[3] Kazumasa Taka, Takashi Kato, Kunio Sawaya, Risaburo Sato "Estimation of Source Location of Leakage Field fromTransformer-type Microwave Oven" Proc. 1991 htemolional Symposium on EAC, Sendai.Iapaq pp. 803, May 1994

[4] Robert F. Schiffmann, Rupert Steiner "Inexpensive Microwave Leakage Detectors" Journal of Microwave Power and Electromagnetic Energy, 46 (3), 2012, pp. 128-138. A Publication of the International Microwave Power Institute

[5] Gopinath Shanmuga Sundaram, Bhanuprasad Patibandala, Harish Santhanam, Sindhura Gaddam "Bluetooth Communication using a Touchscreen Interface with the Raspberry Pi", Electrical and Computer Engineering, University of North Carolina, Southeastcon FL USA, proceeding IEEE Charlotte, 47 April 2013

[6] Nooradzianie Muhammad Zin, Mohammad Zarar Mohamed Jenu, Farhana Ahmad, "Measurements and Reduction of Microwave Oven Electromagnetic Leakage", IEEE International RF and Microwave Conference, Seremban, Malaysia, December 2011.

[7] Microchip MCP 3004/3008, http://www.gogddq.com/downlocal/MCP/MCP3004-3008.pdf

[8] Huey-Ru Chuang, Member, IEEE, and Liang-Chen Kuo, Student Member, IEEE (2002) '3-D FDTD Design Analysis of a 2.4-GHz Polarization-Diversity Printed Dipole Antenna with Integrated Balun and Polarization-Switching Circuit for WLAN and Wireless Communication Applications".

[9] Youping Zhao, Brian G. Agee, Jeffrey H. Reed "Slmulation andc Measurement of M1crowave Oven Leakage for 802.11 WLAN Interference Management" 2005 IEEE International Symposium on Microwave, Antenna, Propagation and EMC Technologies for Wireless Communications Proceedings

[10] Y. Kusama, O. Hashimoto, and M. Makida, "Size reduction of the doorseal structure of a micorwave oven by the FD-TD method," Electronics and Communications in Japan, vol. 86, pp. 73-82, April 2003.

[11] Raspberry Pi User Guide, Eben Upton, Gareth Halfacree, Wiley publication 